\title{
Intensive insulin treatment induces insulin resistance in diabetic rats by impairing glucose metabolism-related mechanisms in muscle and liver
}

\author{
Maristela Mitiko Okamoto, Gabriel Forato Anhê ${ }^{\mathbf{1}}$, Robinson Sabino-Silva, Milano Felipe dos \\ Santos Ferreira Marques, Helayne Soares Freitas, Rosana Cristina Tieko Mori, Karla Fabiana S Melo ${ }^{2}$ \\ and Ubiratan Fabres Machado \\ Department of Physiology and Biophysics, Institute of Biomedical Sciences, University of São Paulo, Avenida Prof. Lineu Prestes, 1524, 05505-900 \\ São Paulo (SP), Brazil \\ ${ }^{1}$ Department of Pharmacology, Faculty of Medical Sciences, State University of Campinas, São Paulo, Brazil \\ ${ }^{2}$ Diabetes Unit, Division of Endocrinology and Metabolism, Medical School, University of São Paulo, São Paulo, Brazil \\ (Correspondence should be addressed to M M Okamoto; Email: mokamoto@icb.usp.br)
}

\begin{abstract}
Insulin replacement is the only effective therapy to manage hyperglycemia in type 1 diabetes mellitus (T1DM). Nevertheless, intensive insulin therapy has inadvertently led to insulin resistance. This study investigates mechanisms involved in the insulin resistance induced by hyperinsulinization. Wistar rats were rendered diabetic by alloxan injection, and 2 weeks later received saline or different doses of neutral protamine Hagedorn insulin $(1 \cdot 5,3,6$, and $9 \mathrm{U} /$ day) over 7 days. Insulinopenic-untreated rats and $6 \mathrm{U}-$ and $9 \mathrm{U}$-treated rats developed insulin resistance, whereas $3 \mathrm{U}$-treated rats revealed
\end{abstract}

the highest grade of insulin sensitivity, but did not achieve good glycemic control as $6 \mathrm{U}$ - and $9 \mathrm{U}$-treated rats did. This insulin sensitivity profile was in agreement with glucose transporter 4 expression and translocation in skeletal muscle, and insulin signaling, phosphoenolpyruvate carboxykinase/ glucose-6-phosphatase expression and glycogen storage in the liver. Under the expectation that insulin resistance develops in hyperinsulinized diabetic patients, we believe insulin sensitizer approaches should be considered in treating T1DM.

Journal of Endocrinology (2011) 211, 55-64

\section{Introduction}

Maintenance of glucose homeostasis depends on insulinstimulated glucose uptake by muscle and adipose cells, brought about by an increase in levels of plasma membrane (PM) glucose transporter 4 (GLUT4; Huang \& Czech 2007). In addition, the liver plays a decisive role in blood glucose homeostasis by maintaining the balance between glucose input (glucose uptake and glycogen synthesis) and output (glycogenolysis and gluconeogenesis; Vidal-Puig \& O'Rahilly 2001). Insulin severely inhibits hepatic glucose output, suppressing gluconeogenesis and glycogenolysis, by inhibiting expression and activity of the key enzymes phosphoenolpyruvate carboxykinase (PEPCK) and glucose6-phosphatase (G6Pase; Barthel \& Schmoll 2003).

Insulin resistance is involved in the pathogenesis of type 2 diabetes mellitus (T2DM; Björnholm \& Zierath 2005). In type 1 diabetes mellitus (T1DM), apart from its well-known pathogenesis, insulin resistance has also been described in both undertreated insulinopenic and well-treated hyperinsulinemic subjects. Insulin resistance in insulinopenic diabetic rats has been associated with impaired glucose disposal in liver and skeletal muscle, similar to T2DM (Camps et al. 1992,
Kainulainen et al. 1994). However, little is known about insulin resistance in hyperinsulinized diabetic subjects.

Reduced GLUT4 protein expression plays an important role in insulin resistance of skeletal muscle, which has been described in experimental models of insulinopenic diabetes (Camps et al. 1992, Kainulainen et al. 1994). Conversely, although short-term hyperinsulinemia in diabetic rats increases GLUT4 expression in adipose tissue (Berger et al. 1989, Sivitz et al. 1989), long periods of hyperinsulinemia in T1DM might induce the contrary, as observed in obese and/or T2DM subjects (Machado et al. 1994, Ledwig et al. 2002).

In the liver, insulin inhibits gluconeogenesis in an insulinreceptor-mediated phosphoinositide 3-kinase and AKT (PI3K/AKT) dependent manner (Withers et al. 1998, Kubota et al. 2000, Michael et al. 2000). After insulin treatment (Andjelković et al. 1997), AKT is known to be translocated into the nucleus, where it can phosphorylate FOXO1. Phosphorylation of FOXO1 leads to nuclear exclusion (Van Der Heide et al. 2004) and to inhibition of FOXO1dependent gene transcription (Biggs et al. 1999, Brunet et al. 1999), such as the genes of PEPCK and G6Pase proteins (Nakae et al. 2001, Altomonte et al. 2003). 
Independent of the degree of insulin deficiency in diabetes, a tight control of blood glucose levels has been proposed to prevent complications and to improve life expectancy (Purnell et al. 1998, DCCT 2001). For that, intensive insulin treatment has been required, leading to peripheral hyperinsulinemia. We believe that hyperinsulinemia might induce insulin resistance; thus, requiring additional care in diabetic subjects. In the light of such concerns, we sought to investigate, in diabetic insulinopenic rats, the effect of different doses of insulin upon insulin sensitivity and the potential molecular mechanisms involved.

\section{Materials and Methods}

\section{Materials}

Neutral protamine Hagedorn (NPH) and regular insulin were purchased from Eli Lilly. Rabbit polyclonal antibodies against p-Tyr, PI3K (p85 $\alpha$ ) and GLUT4 were obtained from Millipore (Bilerica, MA, USA). Rabbit polyclonal antibodies against pAKT 1/2/3 Ser473, pAKT 1/2/3 Thr308, AKT $1 / 2 / 3$ (H-136), IRS-2 (H205), IR $\beta$ (c19), and FOXO1 (H128) were provided by Santa Cruz Biotechnology (Santa Cruz, CA, USA), and rabbit polyclonal antibodies against pGSK3- $\alpha / \beta$ (Ser21/9) and GSK-3 $\beta$ (27C10), by Cell Signaling Technology (Beverly, MA, USA). Secondary antirabbit IgG, conjugated with HRP, and protein A Sepharose $6 \mathrm{MB}$ were obtained from GE Healthcare UK Ltd (Little Chalfont, Buckinghamshire, England). Sodium thiopental was purchased from Cristalia (Itapira, São Paulo, Brazil); alloxan monohydrate, from Sigma-Aldrich; TRIZOL reagent, from Invitrogen (Invitrogen Life Technologies); and TaqMan gene expression (Assay-on-Demand) Rn00689876_m1 (G6Pase, catalytic), Rn01529014_m1 (PEPCK1, cytosolic), and Rn01775763_g1 (glyceraldehyde-3-phosphate dehydrogenase (GAPDH)), from Applied Biosystems (Foster City, CA, USA). All chemicals used in western blotting were purchased from Invitrogen (Invitrogen Life Technologies) and general reagents used in RT-PCR, from Promega.

\section{Animals and treatment}

Male Wistar rats (weighing $\sim 260 \mathrm{~g}$ ) were individually caged in an environment maintained at controlled temperature $\left(23 \pm 2{ }^{\circ} \mathrm{C}\right)$, and lighting $(12 \mathrm{~h}$ light: $12 \mathrm{~h}$ darkness cycle), and allowed free access to water and standard rodent chow diet (Nuvilab CR-1, Nuvital, Curitiba, Brazil). At week 12 of age, the animals were fasted overnight and rendered diabetic (D) by a single i.v. injection of alloxan $(38 \mathrm{mg} / \mathrm{kg} \mathrm{BW})$. Non-diabetic control rats (ND) were injected with the same volume of isotonic $(0 \cdot 9 \% \mathrm{w} / \mathrm{v}) \mathrm{NaCl}$ solution. The animals with polyuria $(>25 \mathrm{ml} /$ day), glycosuria $>++$, but without ketonuria, were chosen for the study. Two weeks later, diabetic rats were subjected to a 7 day treatment with $\mathrm{NPH}$ insulin (I), daily doses of $1.5 \mathrm{U}$ (I1.5), $3 \mathrm{U}$ (I3), $6 \mathrm{U}$ (I6), and
$9 \mathrm{U}$ (I9), divided into two injections (1/3 of the total dose at $0800 \mathrm{~h}$ and the remaining $2 / 3$ at $1700 \mathrm{~h}$ ), or saline (DS), the same volume twice a day. Blood and tissue collection as well as insulin tolerance tests were performed in anesthetized rats (sodium pentobarbital, $40 \mathrm{mg} / \mathrm{kg} \mathrm{BW}$, i.p.), on the day after the end of the treatment. Experimental procedures were approved by the ethics committee for Animal Research of the Institute of Biomedical Sciences of the University of São Paulo (protocol 044/2006).

\section{Intravenous insulin tolerance test}

Tail blood samples were collected in ad libitum fed animals before $(0 \mathrm{~min})$ and $4,8,12$, and $16 \mathrm{~min}$ after i.v. injection of regular insulin $(0 \cdot 75 \mathrm{U} / \mathrm{kg} \mathrm{BW})$. The constant rate for blood glucose disappearance during insulin tolerance test (kITT) was calculated based on the linear regression of the Neperian logarithm of blood glucose concentrations (test strips, Advantage, Roche). The tests were performed from 0900 to $1100 \mathrm{~h}$.

\section{GLUT4 protein analysis by western blotting}

Tissue collection was carried out at $1400 \mathrm{~h}$, in $8 \mathrm{~h}$ fooddeprived rats. Epididymal fat pad and skeletal muscle gastrocnemius were collected before (right side) and $10 \mathrm{~min}$ after (left side) regular insulin injection (4U) in portal vein. For subcellular fractionation, tissue samples were homogenized in sucrose buffer $\mathrm{pH} 7 \cdot 4(10 \mathrm{mmol} / 1$ Tris $-\mathrm{HCl}$, $1 \mathrm{mmol} / \mathrm{l}$ EDTA and $250 \mathrm{mmol} / \mathrm{l}$ sucrose) and subjected to differential centrifugations to obtain PM, microsomalenriched (M), and total membrane (TM) fractions of adipose tissue (Machado et al. 1994) and skeletal muscle (Mori et al. 2008). Protein $(40 \mu \mathrm{g})$ from each sample was subjected to electrophoresis and immunodetection as described (Zanquetta et al. 2006). The blots were quantified by densitometry (ImageQuant TL, Amersham Biosciences UK Limited), and normalized for loading control by densitometry of the lane from the Coomassie stained gel (Ferguson et al. 2005). Finally, GLUT4 protein content was expressed as arbitrary unit per $\mathrm{g}$ of tissue, taking into account the total protein recovery in the sample. GLUT4 translocation index was calculated as follows: GLUT4 translocation index $(\%)=$ PM GLUT4×100/(PM GLUT4+M GLUT4).

\section{G6pase and Pepck $m R N A$ analysis by real-time PCR}

Liver sampling was carried out at $1400 \mathrm{~h}$, in $8 \mathrm{~h}$ fooddeprived animals. Total RNA was isolated using Trizol reagent (Invitrogen), following manufacturer's instructions. Total RNA ( $2 \mu \mathrm{g})$ was used to synthesize cDNA using the IMPRON II Reverse Transcriptase. PCR amplifications were performed by ABI PRISM 7700 heat-cycler detection system (Applied Biosystems), according to the manufacturer's protocol, using specific assay (as described in the section Materials) for each target gene. The level of each gene 
Table 1 Morphometric and metabolic parameters of non-diabetic (ND) and diabetic rats treated with saline (DS) or with neutral protamine Hagedorn insulin at doses of 1·5 (I1 ·5), 3 (I3), 6 (I6), and 9 (I9) U/day. Basal glycemia and insulinemia were measured in blood collected at the beginning (time 0 ) of the insulin tolerance test. Data are mean \pm s.E.M. of 7-13 rats. One-way ANOVA, Student-Newman-Keuls post hoc test. Not all comparisons among insulin-treated groups are shown

\section{Parameters}

Body weight gain (g)

Adipose tissue (g)

Gastrocnemius (g)

Glycosuria (mg/24 h)

Basal plasma glucose $(\mathrm{mg} / \mathrm{dl})$

Basal plasma insulin $(\mu \mathrm{U} / \mathrm{ml})$

\begin{tabular}{|c|c|c|c|c|c|}
\hline ND & DS & $I 1 \cdot 5$ & I3 & 16 & 19 \\
\hline $7 \cdot 69 \pm 0 \cdot 88$ & $1 \cdot 45 \pm 0.59^{+}$ & $15 \cdot 4 \pm 6 \cdot 5^{\ddagger}$ & $32 \cdot 9 \pm 0 \cdot 86^{\pi}$ & $38 \cdot 6 \pm 1 \cdot 20^{\pi}$ & $40 \cdot 9 \pm 4 \cdot 2^{\pi}$ \\
\hline $3 \cdot 54 \pm 0 \cdot 18$ & $1 \cdot 88 \pm 0 \cdot 20^{\dagger}$ & $2 \cdot 31 \pm 0 \cdot 15^{*}$ & $2 \cdot 85 \pm 0 \cdot 14^{\| \prime}$ & $3 \cdot 24 \pm 0 \cdot 27^{\prime \prime}$ & $3 \cdot 05 \pm 0 \cdot 26^{11}$ \\
\hline $1 \cdot 77 \pm 0 \cdot 07$ & $1 \cdot 42 \pm 0 \cdot 10^{*}$ & $1.57 \pm 0.07$ & $1 \cdot 61 \pm 0.05$ & $1 \cdot 63 \pm 0 \cdot 05$ & $1 \cdot 56 \pm 0.06$ \\
\hline Undetectable & $202 \pm 19 \cdot 8$ & $133 \pm 24 \cdot 2^{\|, a}$ & $19 \cdot 0 \pm 10 \cdot 0^{11}$ & $10 \cdot 9 \pm 4 \cdot 7^{\|}$ & $6 \cdot 37 \pm 3 \cdot 2^{\|}$ \\
\hline $106 \pm 4 \cdot 6$ & $408 \pm 22 \cdot 3^{\ddagger}$ & $433 \pm 27 \cdot 8^{\mp, \boldsymbol{q}, \mathrm{a}}$ & $268 \pm 32 \cdot 8^{+, \|}$ & $133 \pm 41 \cdot 3^{9, a}$ & $118 \pm 41 \cdot 3^{\uparrow, a}$ \\
\hline $38 \cdot 8 \pm 1 \cdot 6$ & $12 \cdot 6 \pm 0 \cdot 88^{*}$ & $26 \cdot 9 \pm 1 \cdot 5^{\mathrm{b}}$ & $94 \cdot 1 \pm 8 \cdot 7^{\ddagger, \pi}$ & $115 \pm 7 \cdot 9^{\mp, 9}$ & $220 \pm 14 \cdot 2^{\neq, \boldsymbol{q}, \mathrm{a}}$ \\
\hline
\end{tabular}

${ }^{*} P<0 \cdot 05,{ }^{+} P<0 \cdot 01$, and ${ }^{\ddagger} P<0 \cdot 001$ versus ND; $P<0 \cdot 01$, and ${ }^{\top} P<0 \cdot 001$ versus $\mathrm{DS} ;{ }^{\mathrm{a}} P<0 \cdot 01$ and ${ }^{\mathrm{b}} P<0 \cdot 001$ versus 13 .

expression was related to a Gapdh internal control (Applied Biosystems). All reactions were performed in duplicate and a relative comparison to $\mathrm{ND}$ was made with appropriate cDNA. Resulting gene expression data were calculated and analyzed based on the $2^{-\Delta \Delta C_{\mathrm{t}}}$ method (Pfaffl 2001).

\section{Insulin signaling proteins analysis by western blotting}

Liver sampling was carried out at $1400 \mathrm{~h}$, in $8 \mathrm{~h}$ food-deprived animals. Tissue samples were collected before and $30 \mathrm{~s}$ after a $10 \mathrm{U} /$ rat regular insulin injection in the portal vein (Kubota et al. 2008). Samples were immediately homogenized in ice-cold solubilization buffer, using a Polytron-Aggregate (Luzern, Switzerland) operated at maximum speed for $10 \mathrm{~s}$. The extracts were incubated at $96{ }^{\circ} \mathrm{C}$ for $10 \mathrm{~min}$ and then centrifuged at $12000 \mathrm{~g}$ at $4{ }^{\circ} \mathrm{C}$ for $30 \mathrm{~min}$ to remove insoluble material. Equal amounts of total protein $(100 \mu \mathrm{g}$ protein) were subjected to electrophoresis, transferred to nitrocellulose membrane, and immunodetected with specific antibodies (pAKT-Ser, pAKT-Thr, pGSK, IRS1, IRS2, and IR $\beta$ ). Chemiluminescence was used to generate autoradiograms. Quantitative analysis of blots was performed by ImageQuant TL (Amersham Biosciences UK Limited).

\section{Insulin signaling proteins immunoprecipitation}

Liver samples collected as described earlier were homogenized in immunoprecipitation buffer and then centrifuged at $12000 \mathrm{~g}$ at $4{ }^{\circ} \mathrm{C}$ for $30 \mathrm{~min}$ to remove insoluble material. Supernatants were used for immunoprecipitation with antiIR $\beta$, anti-IRS1, or anti-IRS2 (Anhê et al. 2007). Approximately, $500 \mu \mathrm{g}$ protein from each sample were incubated overnight with $2 \mu \mathrm{g}$ of the specific antibody (see figure legends) and $50 \mu \mathrm{l}$ protein A enriched Sepharose beads. The washed Sepharose beads were treated with Laemmli, subjected to SDS-PAGE and electrotransferred to nitrocellulose membranes. The nitrocellulose membranes were incubated with specific antibodies (phospho-Tyr and PI3K-p85), as described in figure legends and detected as described earlier.

\section{Subcellular distribution of FOXO1}

Cytosolic and nuclear protein fractions from liver samples were obtained based on Andrews and Faller method (Andrews \& Faller 1991). Briefly, samples were pulverized in liquid nitrogen and resuspended in ice-cold PBS with dithiothreitol (DTT; $200 \mu \mathrm{M}$ ) and phenylmethylsulphonyl fluoride (PMSF; $200 \mu \mathrm{M})$. After centrifugation at $1000 \mathrm{~g}$ $\left(10 \mathrm{~min}, 4^{\circ} \mathrm{C}\right)$ the supernatant was recovered as the cytosolic fraction. The pellet was incubated $\left(10 \mathrm{~min}, 4^{\circ} \mathrm{C}\right)$ with hypotonic buffer (10 mM HEPES pH 7.9, $1.5 \mathrm{mM} \mathrm{MgCl}$, $10 \mathrm{mM} \mathrm{KCl}, 0 \cdot 2 \mathrm{mM}$ DTT, $0 \cdot 2 \mathrm{mM}$ PMSF). NP-40 (10\%) was added, and samples were then centrifuged at $15000 \mathrm{~g}$ $\left(30 \mathrm{~s}, 4{ }^{\circ} \mathrm{C}\right)$. High salt extraction buffer $(20 \mathrm{mM}$ HEPES $\mathrm{pH}$ 7.9, $1.5 \mathrm{mM} \mathrm{MgCl}, 0.5 \mathrm{mM}$ EDTA, 0.2 mM DTT, $0.2 \mathrm{mM}$ PMSF, $420 \mathrm{mM} \mathrm{NaCl}$ ) was added to the pellet, providing nucleus lyses after a $20 \mathrm{~min}$ incubation at $4{ }^{\circ} \mathrm{C}$. The supernatant yielded by centrifugation at $12000 \mathrm{~g}$ (2 min)

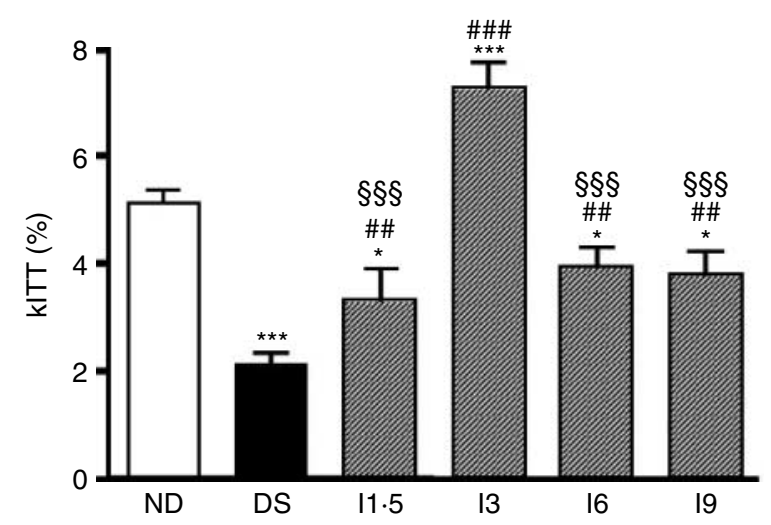

Figure 1 Effect of insulin treatment on insulin sensitivity. Diabetic rats underwent a 7 day treatment with saline (DS) or with $\mathrm{NPH}$ insulin (I) at daily doses of 1.5U (I1.5), 3U (I3), 6U (I6), and 9U (I9). Non-diabetic rats (ND) were analyzed as control group. kITT, constant rate for blood glucose disappearance during insulin tolerance test. Data are mean \pm S.E.M. of 7-13 animals. One-way ANOVA followed by Student-Newman-Keuls. Not all comparisons among insulin-treated groups are shown. ${ }^{*} P<0.05$ and ${ }^{* * *} P<0.001$ versus ND; ${ }^{\#} P<0.01$ and ${ }^{\# \#} P<0.001$ versus DS; $\S \S \$ P<0 \cdot 001$ versus 13 . 
was recovered as nuclear fraction. Cytosolic and nuclear proteins $(100 \mu \mathrm{g})$ were used for immunodetection of FOXO1, as described in previous sections.

Plasma glucose, plasma insulin, and liver glycogen

Plasma and urine samples were assayed for glucose by Glicose Enzimática kit (ANALISA Diagnostica, Belo Horizonte, MG, Brazil). Plasma was also assayed for insulin by Coat-A-Count kit (DPC Diagnostic Products, Los Angeles, CA, USA). Glycogen was extracted from $100 \mathrm{mg}$ of liver samples collected as described earlier. Samples were treated for glycogen breakdown, pelleted with ethanol and saturated $\mathrm{Na}_{2} \mathrm{SO}_{4}$, and resuspended for final measurement of glucose concentration.

\section{Statistical analysis}

Data are expressed as mean \pm s.E.M. The number of animals or experiments is indicated in legends. Comparisons among the groups were made by one-way ANOVA, followed by Student-Newman-Keuls as post hoc test. Basal and insulin-stimulated conditions were compared by paired Student's $t$-test.

\section{Results}

Morphometric and metabolic parameters of diabetic rats treated or not with insulin

Table 1 shows that diabetes induced lower body weight gain $(\sim 19 \%$ of ND value, $P<0 \cdot 01)$, and decreased adipose $(53 \%$ of ND value, $P<0 \cdot 01$ ) and muscle ( $80 \%$ of ND value, $P<0.05)$ tissue weights. As expected, high plasma glucose (approximately fourfold, $P<0 \cdot 001$ ) and low plasma insulin $(1 / 3, P<0 \cdot 05)$ levels, as well as pronounced glycosuria were observed in saline-treated diabetic animals. Increased body weight $(P<0 \cdot 001)$ and fat mass $(P<0 \cdot 01)$, were found in I3-, I6-, and I9-treated diabetic rats, compared with saline-treated rats. Insulin treatment reduced glycosuria and plasma glucose in diabetic rats in a dose-dependent manner. Higher doses of I6 and I9 were able to decrease plasma glucose levels to values similar to those found in ND rats. However, this glycemic control was achieved with plasma insulin levels three- and sixfold higher than ND, respectively, for I6 and I9 $(P<0 \cdot 001)$.

\section{Effect of different doses of insulin replacement on insulin sensitivity of diabetic rats}

As indicated by the insulin tolerance test (Fig. 1), diabetic rats showed a significant decrease in insulin sensitivity $(41 \%$ of ND, $P<0 \cdot 001)$. The $1 \cdot 5,6$, and $9 \mathrm{U}$ doses increased $(P<0 \cdot 05$ to $P<0 \cdot 01$ versus DS) the kITT, but did not restore it to ND value $(P<0.05$ versus ND). Treatment with $3 \mathrm{U}$ of insulin maximally increased the kITT value $(3 \cdot 5$-fold versus DS, $P<0 \cdot 001)$, reaching value approximately twofold higher than
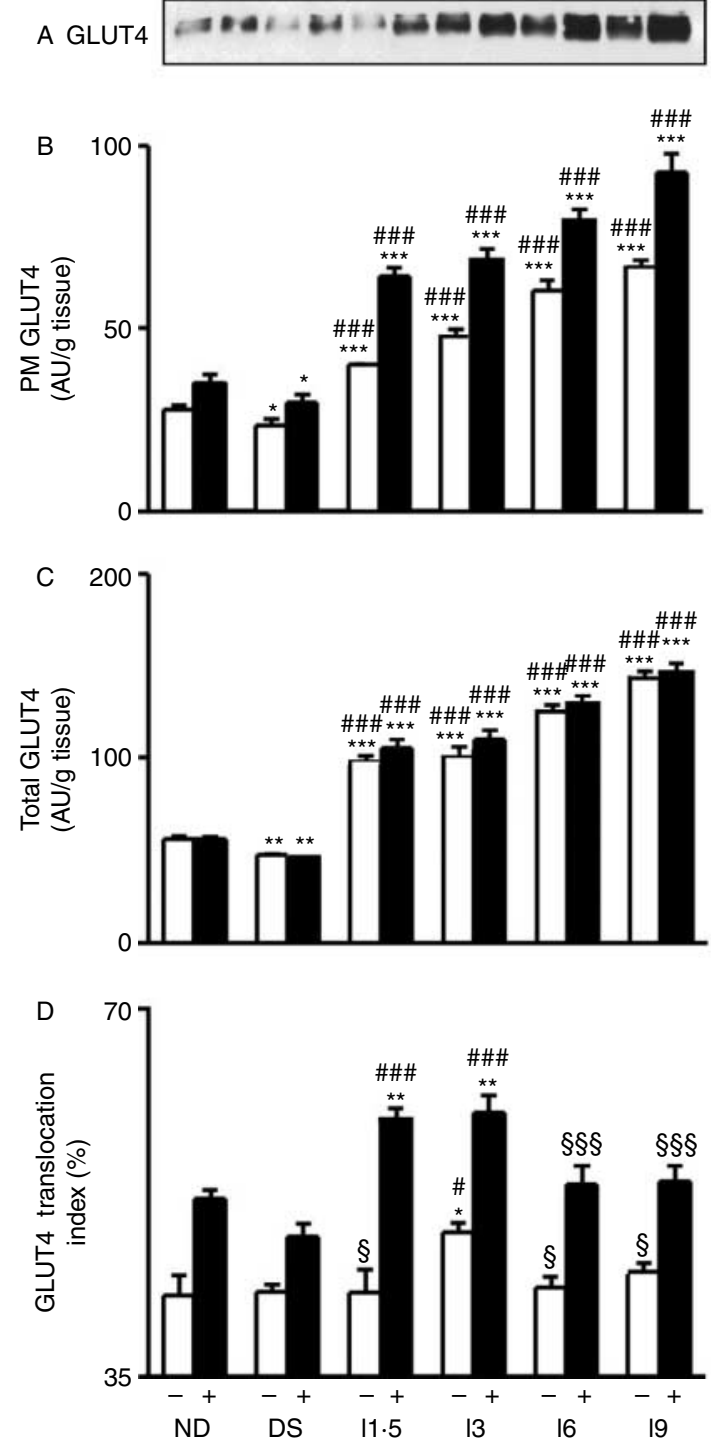

Figure 2 Effect of insulin treatment on basal and insulin-stimulated GLUT4 protein content in white adipose tissue. Diabetic rats underwent a 7 day treatment with saline (DS) or with NPH insulin (I) at daily doses of $1 \cdot 5 \mathrm{U}(11 \cdot 5), 3 \mathrm{U}(\mathrm{I3}), 6 \mathrm{U}(\mathrm{I6})$, and $9 \mathrm{U}(19)$. Nondiabetic rats (ND) were analyzed as control group. Periepididymal fat pad was collected before $(-)$ and 10 min after $(+)$ insulin injection (4U/rat). GLUT4 protein was assessed in plasma membrane (PM) and microsomal (M) fractions. (A) Typical autoradiogram of GLUT4 protein in PM samples according to the sequence presented at the bottom. (B) PM GLUT4 protein content expressed as arbitrary units (AU) per g of tissue. (C) Total GLUT4 content (PM+M) expressed by g of tissue. (D) Translocation index, showing the PM GLUT4 content as a percentage of the total GLUT4. Data are mean \pm S.E.M. of six animals. One-way ANOVA followed by StudentNewman-Keuls was used to compare groups under the same condition (basal or insulin-stimulated). Not all comparisons among insulin-treated groups are shown. Paired Student's $t$-test showed a significant difference between basal $(-)$ and insulin-stimulated (+) conditions for all groups in panels $\mathrm{B}$ and $\mathrm{D}$ (not shown). ${ }^{*} P<0 \cdot 05$, ${ }^{* *} P<0.01$, and ${ }^{* * *} P<0.001$ versus ND; ${ }^{\#} P<0.05$ and ${ }^{\# \# \#} P<0.001$ versus DS; ${ }^{\S} P<0.05$ and ${ }^{\S \S \S} P<0.001$ versus 13 . 
that observed in I1·5-, I6-, and I9-treated rats $(P<0 \cdot 001)$, and even higher than that observed in ND rats $(50 \%$, $P<0 \cdot 001)$.

I3 treatment increases adipose and muscle GLUT4 content and translocation

Figure 2 shows GLUT4 protein analysis in white adipose tissue. Figure $2 \mathrm{~B}$ shows that diabetes decreased the GLUT4 content in PM $(P<0 \cdot 05)$, and insulin treatment induced a dose-dependent increase in GLUT4 in both basal and insulinstimulated conditions $(P<0 \cdot 001$ versus ND and DS). A similar pattern is observed in total GLUT4 protein, measured in samples containing total cellular proteins (Fig. 2C). By relating PM GLUT4 content to total GLUT4 content (both expressed in AU/g of tissue), the percentage of total GLUT4 present in the PM at the moment of tissue withdrawal, referred to as translocation index (Fig. 2D), was obtained. Although the translocation index was not altered by diabetes, I3-treated group was the only one to show both basal and insulin-stimulated translocation index higher than DS and ND $(P<0 \cdot 05$ to $P<0 \cdot 001)$. Importantly, I6 and I9 treatments decreased this parameter $(P<0 \cdot 001)$ compared with I3. Finally, acute effects of insulin were observed in all groups (panels B and C), comparisons not shown in the figure.

Figure 3 shows GLUT4 protein analysis in gastrocnemius skeletal muscle. Figure $3 \mathrm{~B}$ shows that diabetes decreased GLUT4 in PM $(P<0.001)$ in both basal and insulinstimulated conditions. I3-treated diabetic animals were able to increase GLUT4 protein $(P<0.001$ versus DS), under both conditions, to values similar to ND; and higher $(P<0 \cdot 001)$ than those observed in I1.5-, I6-, and I9-treated rats. A similar pattern of results was found in total GLUT4 protein, measured in samples containing TM proteins (Fig. 3C). Only I3- and I6-treated rats were able to restore the total GLUT4 content to ND levels. Figure 3D shows the translocation index. Although diabetes did not alter this parameter, once again I3-treated animals showed the maximal increase, reaching values higher than those observed in I1.5-, I6-, and I9-treated rats $(P<0 \cdot 05$ to $P<0 \cdot 01)$. In addition, as in adipose tissue, acute insulin effect upon GLUT4 translocation to PM (Fig. 3B and C) was observed in all experimental conditions (statistics not shown in the figure).

I3 treatment represses Pepck and G6pase gene expression and enhances glycogen content in liver

Similar regulations of the mRNA expression of Pepck (Fig. 4A) and G6pase (Fig. 4B) enzymes were observed. Diabetes increased Pepck and G6pase mRNA content (approximately twofold, $P<0.05$ ), and I3 treatment decreased both to levels of ND rats. Importantly, I6 and I9 treatments had the opposite effect, increasing these mRNAs to values higher than those observed in ND and DS $(P<0 \cdot 01$ to $P<0 \cdot 001)$. As a consequence of the regulation of these enzymes, glycogen storage was conversely modulated
A
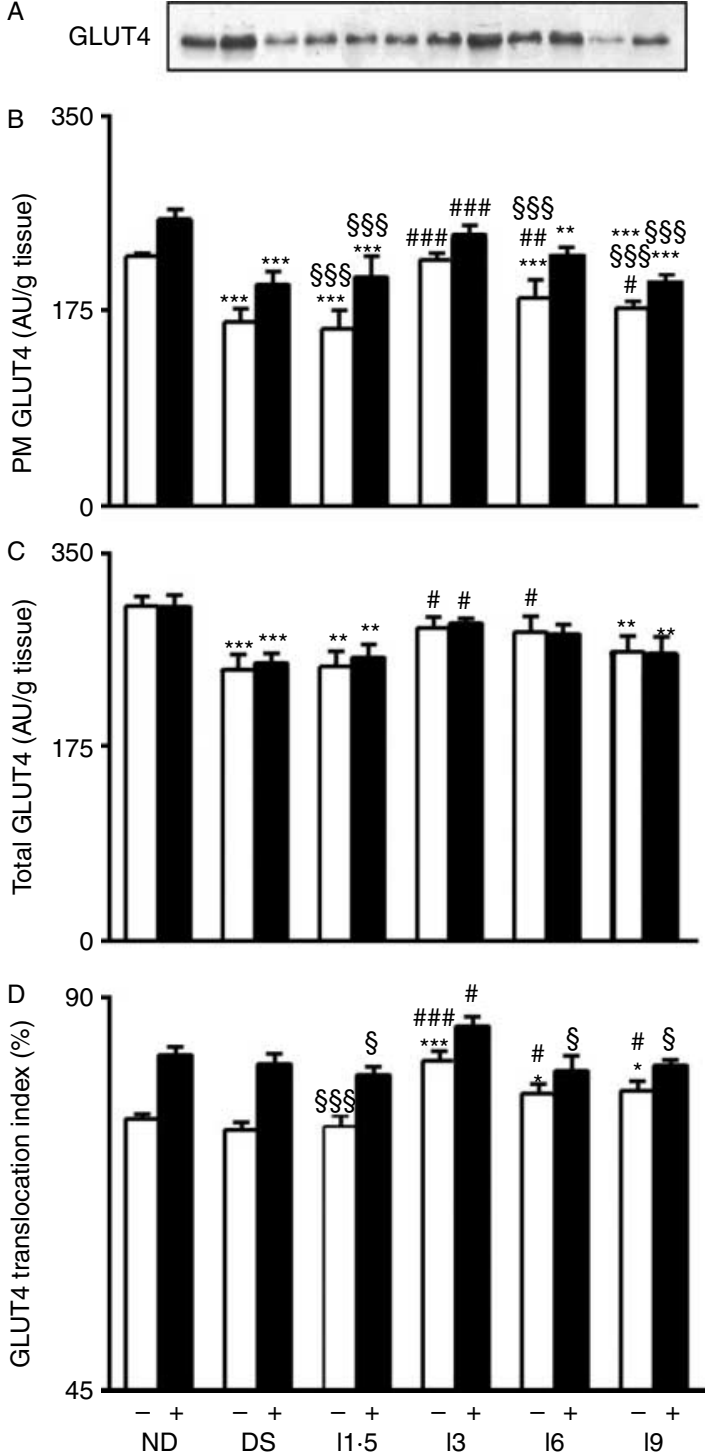

Figure 3 Effect of insulin treatment on basal and insulin-stimulated GLUT4 protein content in skeletal muscle. Diabetic rats underwent a 7 day treatment with saline (DS) or with NPH insulin (I) at daily doses of $1 \cdot 5 \mathrm{U}(\mathrm{I1} \cdot 5), 3 \mathrm{U}(\mathrm{I3}), 6 \mathrm{U}(\mathrm{I6})$, and $9 \mathrm{U}(\mathrm{I9})$. Non-diabetic rats (ND) were analyzed as control group. Gastrocnemius was collected before $(-)$ and $10 \mathrm{~min}$ after $(+)$ insulin injection (4U/rat). GLUT4 protein was assessed in plasma membrane (PM) and microsomal (M) fractions. (A) Typical autoradiogram of GLUT4 protein in PM samples according to the sequence presented at the bottom. (B) PM GLUT4 protein content expressed as arbitrary units (AU) per g of tissue. (C) Total GLUT4 content (PM+M) expressed by g of tissue.

(D) Translocation index, showing the PM GLUT4 content as a percentage of the total GLUT4. Data are mean \pm S.E.M. $n=6$. One-way ANOVA followed by Student-Newman-Keuls was used to compare groups under the same condition (basal or insulin-stimulated). Not all comparisons among insulin-treated groups are shown. Paired Student's $t$-test showed a significant difference between basal (-) and insulin-stimulated $(+)$ conditions for all groups in panels $B$ and $D($ not shown). ${ }^{*} P<0 \cdot 05,{ }^{* *} P<0 \cdot 01$, and ${ }^{* * *} P<0.001$ versus ND; ${ }^{*} P<0.05$ and ${ }^{\# \#} P<0.001$ versus DS; ${ }^{\$} P<0.05$ and ${ }^{\$ \$ \$} P<0.001$ versus $I 3$. 


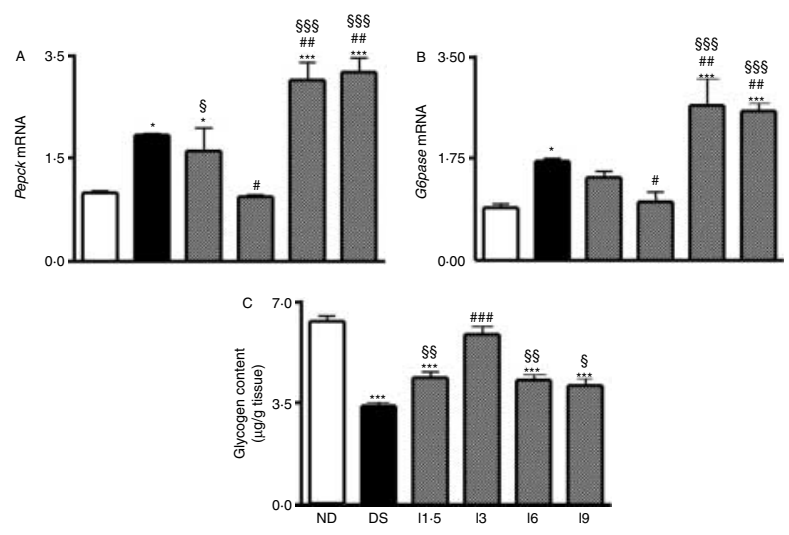

Figure 4 Effect of insulin treatment on liver phosphoenolpyruvate carboxykinase (Pepck) and glucose-6-phosphatase (G6pase) mRNA expression, and on glycogen content. Diabetic rats underwent a 7 day treatment with saline (DS) or with NPH insulin (I) at daily doses of $1 \cdot 5 \mathrm{U}(\mathrm{I1} \cdot 5), 3 \mathrm{U}(\mathrm{I3}), 6 \mathrm{U}(\mathrm{I6})$, and $9 \mathrm{U}(\mathrm{I9})$. Non-diabetic rats (ND) were analyzed as control group. Pepck and G6pase mRNAs were related to GAPDH as internal control, and expressed as arbitrary units. Data are mean \pm s.E.M. of six to seven animals. One-way ANOVA, Student-Newman-Keuls as post hoc test. Not all comparisons among insulin-treated groups are shown. ${ }^{*} P<0.05$ and ${ }^{* * *} P<0.001$ versus ND; ${ }^{\#} P<0.05,{ }^{\#} P<0.01$, and ${ }^{\# \#} P<0.001$ versus DS; ${ }^{\S} P<0 \cdot 05,{ }^{\S \S} P<0 \cdot 01$, and ${ }^{\S \S \S} P<0 \cdot 001$ versus I3.

(Fig. 4C). Diabetes decreased glycogen content to $\sim 50 \%$ of ND $(P<0 \cdot 001)$, I3 treatment increased it to a value similar to that observed in ND, and I6 and I9 decreased it again (respectively, $P<0 \cdot 01$ and $P<0 \cdot 05$ versus I3).

\section{I3 maximally increases insulin signaling in liver}

Figure 5A shows that diabetes decreased basal and insulinstimulated tyrosine phosphorylation of $\operatorname{IR} \beta(P<0 \cdot 05)$. Maximal upregulation of basal and insulin-stimulated tyrosine phosphorylation of IR $\beta$ was achieved with $3 \mathrm{U}$ of insulin. Compared with I3 effect, I6 and I9 treatments decreased the IR $\beta$ phosphorylation in basal and insulin-stimulated conditions $(P<0 \cdot 05$ to $P<0 \cdot 001)$. Figure $5 \mathrm{~B}$ demonstrates that diabetes did not alter basal IRS2 tyrosine phosphorylation, but this parameter was equally upregulated by all doses of insulin treatment $(P<0 \cdot 001$ versus ND and DS). Insulinstimulated IRS2 tyrosine phosphorylation was decreased in $\mathrm{D}$ rats $(P<0 \cdot 001)$, and $\mathrm{I} 3, \mathrm{I} 6$, and $\mathrm{I} 9$ treatments increased this phosphorylation, with maximal effect observed in I3 dose $(P<0.001$ versus DS). Figure 5C shows that, compared with IRS2 phosphorylation, IRS2 in association with PI3K was similarly regulated, showing maximal improvement in I3-treated rats, both under basal and insulin-stimulated conditions $(P<0 \cdot 05$ to $P<0 \cdot 001$ versus I1.5, I6, and I9). Figure 5D shows that, despite unchanged threonine phosphorylation of AKT in DS animals, I3 treatment induced the maximal increase in this parameter, mainly under insulin-stimulated condition $(P<0 \cdot 001$ versus I6 and I9). Similar results were observed for serine phosphorylation of AKT (Fig. 5E), except for the fact that maximal effects of I3 were more evident under basal condition. Figure $5 \mathrm{~F}$ shows diabetes-induced reduction in basal and insulin-stimulated GSK3 phosphorylation $(P<0 \cdot 001$ versus ND). Under basal condition, maximal recovery of GSK3 phosphorylation was observed in I3-treated rats $(P<0.001$ versus $\mathrm{I} 1.5$ and I6; $P<0.05$ versus 19$)$. Under insulin-stimulated condition, GSK3 phosphorylation increased with I3 $(P<0 \cdot 001)$, but also with I6 and I9 $(P<0 \cdot 05)$ treatments. Finally, in accordance with the representative immunoblots of total IR $\beta(5 \mathrm{~A})$, total IRS2 (5B), total AKT (5D and 5E), and total GSK3 (5F) protein contents, no differences were observed among the groups.

\section{I3 recovers cytoplasmic accumulation of FOXO1 in the liver}

Insulin-mediated reduction in G6pase and in Pepck is achieved by cytoplasmic arresting of the transcription factor FOXO1 (Mounier \& Posner 2006). Increased cytoplasmic accumulation of FOXO1 is facilitated by its phosphorylation via AKT. To correlate our findings of Pepck and G6pase mRNA contents with insulin signaling, we then assessed FOXO1 relative content in cytoplasm as a parameter of its cytoplasmic arresting. Figure 6 shows the cytoplasmic and nuclear content of FOXO1. The cytoplasmic/nuclear level of FOXO1 is decreased in D rats $(46 \%, P<0 \cdot 001)$. Replacement with high doses of insulin (6 and $9 \mathrm{U} /$ day) resulted in partial recovery of cytoplasmic/nuclear levels of Foxo1 ( $\sim 72 \%$ of ND values, $P<0 \cdot 05)$. However, $3 \mathrm{U}$ of insulin totally recovered cytoplasmic/nuclear FOXO1 level, to a value similar to that found in ND rats, and significantly higher than that observed in rats treated with $1 \cdot 5,6$, and $9 \mathrm{U}$ of insulin $(P<0 \cdot 05)$.

\section{Discussion}

This study was designed to investigate: 1) whether hyperinsulinization of diabetic rats, required for good glycemic control, induces insulin resistance, and 2) the potential territories and molecular mechanisms involved. The main finding of our study was that, in fact, high doses (6 and $9 \mathrm{U} /$ day) of insulin induced important insulin resistance, whereas the intermediate dose of $3 \mathrm{U} /$ day induced maximal improvement on insulin sensitivity, although glycemic control was not achieved. Furthermore, because of altered GLUT4 expression/translocation in skeletal muscle and PEPCK/G6Pase expression in the liver, these territories were pointed out as being involved in the modulations of insulin sensitivity.

In this study, we used alloxan for diabetes induction because it is known to lead ketosis-prone diabetes in rat that resembles human T1DM (Federiuk et al. 2004). Besides, alloxan is as effective as streptozotocin and the same grade of $\beta$-cell loss can be achieved with both drugs; thus, no differences are to be expected between the models (Lenzen 2008). Although insulin resistance is pathognomonic of T2DM, it was also observed in streptozotocin-treated rats 

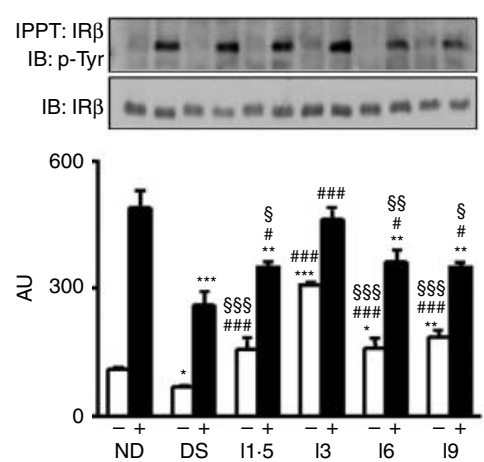

D
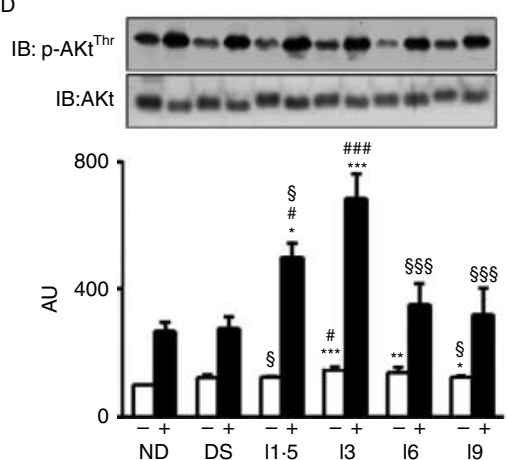
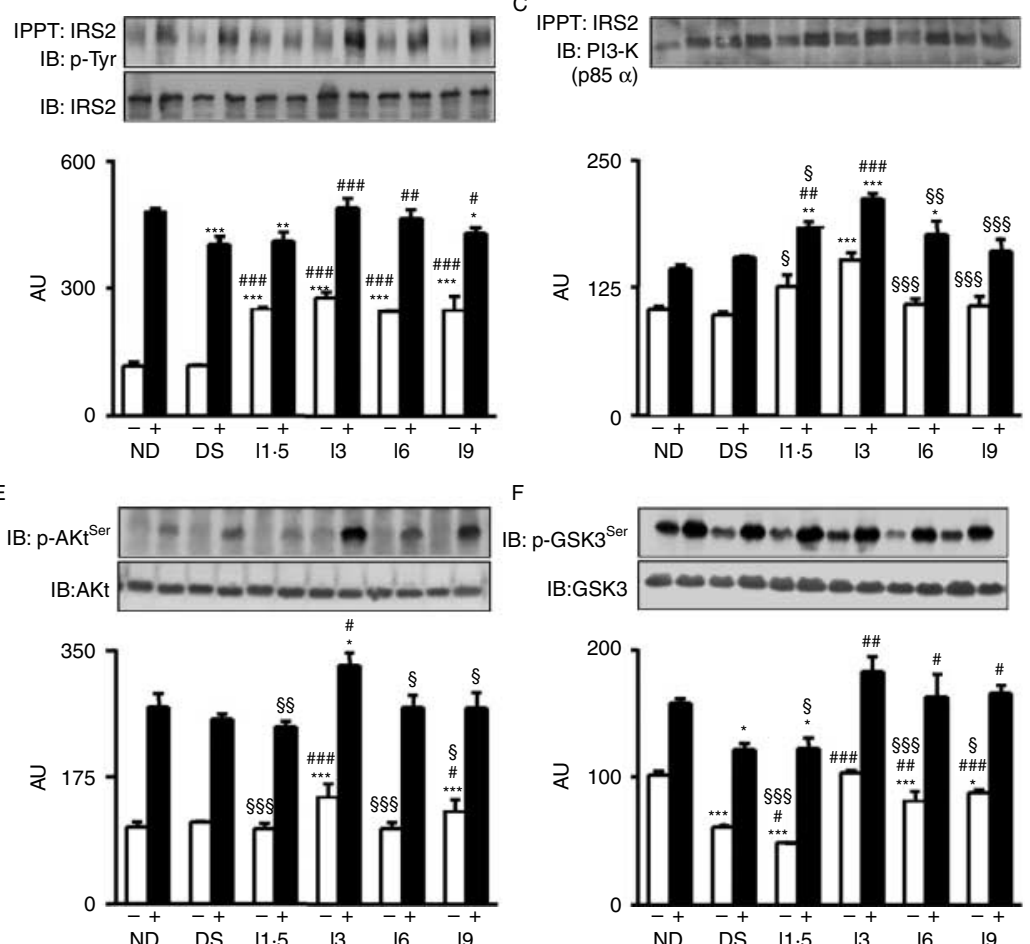
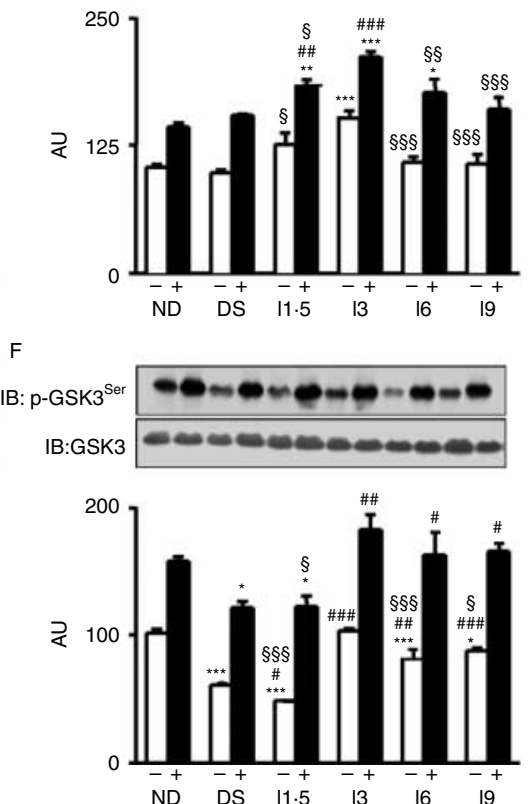

Figure 5 Effect of insulin treatment on liver insulin signaling. Diabetic rats underwent a 7 day treatment with saline (DS) or with $\mathrm{NPH}$ insulin (I) at daily doses of $1 \cdot 5 \mathrm{U}$ (I1.5), $3 \mathrm{U}$ (I3), 6U (I6), and 9U (I9). Non-diabetic rats (ND) were analyzed as control group. Liver samples were collected before $(-)$ and after $(+)$ insulin injection $(10 \mathrm{U} / \mathrm{rat})$ in portal vein. Aliquots containing the same amount of protein were immunoprecipitated (IPPT) with anti-Ir $\beta$ (A) and anti-IRS2 (B and C) antibodies and immunoblotted (IB) with antiphosphotyrosine antibody (A and B). Membrane with IRS2 immunoprecipitated was stripped and reprobed with anti-PI3K antibody (subunit $\mathrm{p} 85 \alpha$ ) for association analysis (C). For total protein analysis, membranes were stripped and reprobed with respective antibodies. At the top of each panel, representative autoradiogram of phosphorylated protein (upper) and total protein content (lower). (A) Tyrosine phosphorylation of insulin receptor IR $\beta$-subunit; (B) tyrosine phosphorylation of IRS2; (C) IRS2 and PI3K association; (D) threonine (Thr) phosphorylation of AKT; (E) serine (Ser) phosphorylation of AKT; (F) serine phosphorylation of GSK3. In panels A, B, D, E, and F graphs correspond to the amount of phosphorylated proteins, and the amount of total proteins are not shown in graphs since they did not vary among the groups. Data are mean \pm s.E.M. of six animals. One-way ANOVA followed by Student-Newman-Keuls was used to compare groups under the same condition (basal or insulin-stimulated). Not all comparisons among insulin-treated groups are shown. Paired Student's $t$-test revealed significant differences between basal $(-)$ and insulin-stimulated ( + ) conditions for all groups (not shown), except for the total protein content. ${ }^{*} P<0 \cdot 05,{ }^{* *} P<0 \cdot 01$, and ${ }^{* * *} P<0 \cdot 001$ versus ND; ${ }^{\#} P<0 \cdot 05$, ${ }^{\#} P<0 \cdot 01$, and ${ }^{\# \# \#} P<0 \cdot 001$ versus DS; ${ }^{\S} P<0 \cdot 05,{ }^{\S \S} P<0 \cdot 01$, and ${ }^{\S \S \S} P<0 \cdot 001$ versus 13 .

(Blondel \& Portha 1989), and we now show the same effect in alloxan-treated rats.

Some metabolic alterations, as observed here, have already been pointed out to contribute to insulin resistance in hypoinsulinemic diabetic rats, such as deficient GLUT4 expression and translocation in skeletal muscle (Liu et al. 2010) and increased hepatic glucose output (Blondel \& Portha 1989, Burcelin et al. 1995). Now, we show in the liver of diabetic rats that: 1) GSK3 activation decreased, contributing to impaired glycogen synthesis and 2) nuclear content of FOXO1 decreased, which concurs with the increased expression of FOXO1-dependent genes, such as Pepck and G6pase, contributing to enhanced gluconeogenesis and glucose outflow. In this regard, excess glucocorticoids and free fatty acids were demonstrated as able to impair insulin-induced suppression of endogenous glucose production in diabetic rats (Bitar 2001). Besides, hyperglycemia per se may also be involved in the insulin resistance observed in untreated diabetic rats.

In this study, the most important findings are related to insulin resistance as a consequence of therapeutic intervention. Insulin resistance has been described in diabetic insulintreated patients (DeFronzo 1997), and despite its impact on glycemic control, the inadvertent insulin resistance can be deleterious. In fact, intensive insulin therapy in T1DM has already been correlated with an increased incidence of some complications of diabetes such as microangiopathy (Uruska et al. 2010).

A focus of this study was determining molecular mechanisms involved in the insulin therapy-induced changes 


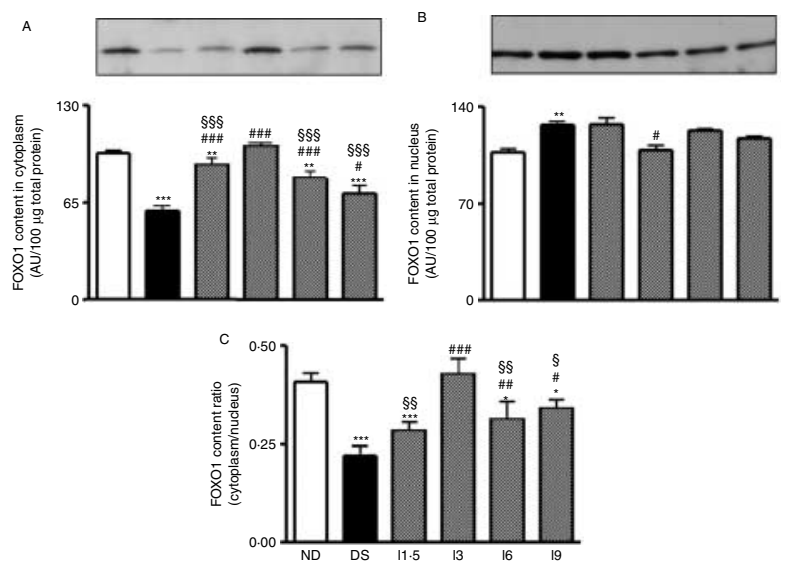

Figure 6 Effect of insulin treatment on liver FOXO1 protein expression and subcellular localization. Diabetic rats underwent a 7 day treatment with saline (DS) or with NPH insulin (I) at daily doses of $1 \cdot 5 \mathrm{U}(\mathrm{I1} \cdot 5), 3 \mathrm{U}(\mathrm{I3}), 6 \mathrm{U}(\mathrm{I6})$, and $9 \mathrm{U}(\mathrm{I9})$. Non-diabetic rats (ND) were analyzed as control group. (A) Western blotting analysis of FOXO1 protein in cytoplasm: at the top, representative autoradiogram and at the bottom, cytoplasmic FOXO1 content expressed as $\mathrm{AU} / 100 \mu \mathrm{g}$ of total protein subjected to electrophoresis. (B) Western blotting analysis of FOXO1 protein in nucleus: at the top, representative autoradiogram and at the bottom, cytoplasmic FOXO1 content expressed as AU/100 $\mu \mathrm{g}$ of total protein subjected to electrophoresis. (C) Cytoplasmic/nuclear FOXO1 content ratio. Data are mean \pm s.E.M. of six animals. One-way ANOVA, StudentNewman-Keuls as post hoc test. Not all comparisons among insulintreated groups are shown. ${ }^{*} P<0 \cdot 05, * * P<0 \cdot 01$, and $* * * P<0 \cdot 001$ versus ND; ${ }^{\#} P<0.05,{ }^{\# \#} P<0 \cdot 01$, and ${ }^{\# \#} P<0.001$ versus DS; ${ }^{\S} P<0 \cdot 05,{ }^{\S} P<<0 \cdot 01$, and ${ }^{\S \S \S} P<0 \cdot 001$ versus 13 .

in insulin sensitivity. Adipose tissue and skeletal muscle were our first focus, since impaired glucose disposal in these tissues is currently involved in insulin resistance. Taking this into consideration, we investigated how the range of insulin dosages used herein would interfere with GLUT4 expression and translocation into PM, which have been currently involved in insulin resistance (Wallberg-Henriksson \& Zierath 2001).

In adipose tissue, we found that increasing doses of insulin progressively upregulate total cellular GLUT4 content, as well as its translocation to the PM, which does not match with the dose effects observed in insulin sensitivity. In contrast, in transgenic mice overexpressing GLUT4 selectively in adipose tissue, whole-body insulin sensitivity improves, but this may be accounted for by the fact that in transgenic mice the GLUT4 protein increase is enormous (10-20 times), and the plasma insulin levels show a compensatory decrease (Shepherd et al. 1993, Carvalho et al. 2005). On the other hand, the present results also indicate a progressive increase in local insulin sensitivity in adipose tissue, which is in agreement with the progressive fat mass gain observed. Actually, weight gain and even obesity have been related to intensive insulin treatment of type 1 diabetic subjects (DCCT 2001). In contrast to what we observed in adipose tissue, GLUT4 expression and translocation in skeletal muscle of diabetic rats reached the maximal improvement with the intermediate insulin dose of $3 \mathrm{U}$; and high doses of $6 \mathrm{U}$ and $9 \mathrm{U}$ decreased the GLUT4 translocation. This profile of hyperinsulinemiainduced modulation of GLUT4 in muscle is in accordance with that observed in whole-body insulin sensitivity, and reveals the muscle participation in hyperinsulinemia-induced insulin resistance, as observed in untreated-diabetic rats.

Increased hepatic and renal glucose outflow are known to play important roles in hyperglycemia. This may occur due to insulin resistance, as in T2DM (Meyer et al. 1998, Gerich 2010) or lack of insulin, as in T1DM (Blondel \& Portha 1989, Burcelin et al. 1995). Insulin inhibits glucose outflow mostly by decreasing gluconeogenesis; but also by decreasing breakdown and increasing synthesis of glycogen (Blondel \& Portha 1989, Burcelin et al. 1995). Several indirect and direct mechanisms have been described as involved in insulinregulated inhibition of hepatic glucose production (Girard 2006). However, three mechanisms have been pointed out:

1) inhibition of PEPCK, key enzyme for gluconeogenesis; 2) stimulation of GSK3, key enzyme for glycogen synthesis; and 3) inhibition of G6Pase, responsible for glucose-6phosphate dephosphorylation, key step to obtain glucose, which is able to cross throughout the GLUT2 transporter (O'Brien et al. 2001). In this context, we found that the intermediate dose of $3 \mathrm{U}$ maximally reduced Pepck and G6pase expression and increased serine phosphorylation of GSK3, highligting the participation of liver in the maximal effect of this insulin dose on whole-body insulin sensitivity improvement. Notably, all these parameters were impaired by the doses of $6 \mathrm{U}$ and $9 \mathrm{U}$ of insulin, despite the better glycemic control promoted by such high doses. In accordance with all these enzymes regulations, hepatic glycogen content was highest in 3U-treated diabetic rats, and decreased in 6U- and 9 U-treated rats, reinforcing the effects of insulin therapy upon hepatic insulin sensitivity and; consequentially, on glucose outflow. According to that, increased fat accumulation secondary to excessive insulin replacement has already been proposed as able to induce liver insulin resistance (Liu et al. 2009).

Mechanisms of PEPCK, G6Pase and GSK3 regulation are related to intracellular insulin signaling which was also investigated. After insulin binding to its receptor (IR), tyrosine autophosphorylation of IR is a key step to trigger intracellular insulin signaling (Taniguchi et al. 2006). Our data show that insulin-induced tyrosine phosphorylation of IR is reduced in liver of untreated and $6 \mathrm{U}$ - and $9 \mathrm{U}$-treated diabetic rats, being maximally upregulated in the liver of $3 U$-treated diabetic rats. Sequential events downstream of IR phosphorylation, such as IRS2/PI3K association (an important step for insulinmediated inhibition of gluconeogenesis) (Taniguchi et al. 2006, Guo et al. 2009), were concordantly regulated. In addition, AKT phosphorylation in both serine and threonine also revealed the same regulation: i.e. decreased in insulinopenic diabetic rats, maximal upregulation in $3 \mathrm{U}$-treated diabetic rats, and decreased again in $6 \mathrm{U}$ - and $9 \mathrm{U}$-treated rats.

The present results in the liver suggest that regulation of IRS2 by insulin, irrespective of IRS1, is enough to control 
levels of PEPCK and G6Pase expression, as well as GSK3 activation. Although it has been initially suggested that IRS1 is linked to glucose homeostasis, while IRS2 would be related to lipid metabolism (Taniguchi et al. 2005), recent studies using Irs 2 knockout mice have shown hepatic insulin resistance and increased gluconeogenesis, showing the importance of IRS2 in hepatic glucose metabolism. In addition, an important difference between IRS1 and IRS2 signaling branches has recently been determined, showing that IRS2, but not IRS1 deficient mice present hepatic insulin resistance in insulinopenic situations such as fasting (Kubota et al. 2008). This corroborates the results currently observed in our insulinopenic diabetic rats.

Insulin-induced suppression of PEPCK and G6Pase expression involves the phosphorylation/activation of AKT and the downstream repression of FOXO1 transcriptional activity by decreasing its nuclear content (Yeagley et al. 2001, Van Der Heide et al. 2004). In accordance with that, we now show that high insulin doses of $6 \mathrm{U}$ and $9 \mathrm{U}$ decreased AKT activation, and increased nuclear FOXO1 accumulation, which concur with the enhanced PEPCK and G6Pase expression observed. In accordance with our findings, it has been demonstrated that the absence of IRS2 in hepatocytes results in decreased AKT and increased PEPCK and G6Pase expression (Valverde et al. 2003).

Altogether, data collected in diabetic rats herein show that insulin therapy with high doses of insulin (necessary to achieve good glycemic control) induced insulin resistance, whereas an intermediate dose optimally improved insulin sensitivity, but did not normalize glycemia. Both up- and downregulations of insulin sensitivity were accompanied by concordant modulations of GLUT4 expression and translocation in skeletal muscle, and insulin signaling, PEPCK/G6Pase expression, and glycogen storage in the liver. These results highlight the participation of muscle and liver in the glucose homeostasis of insulin-treated diabetic rats. Accordingly, the expectation of insulin resistance development in hyperinsulinized diabetic patient must be kept in mind, and insulin sensitizer approaches should be considered in these states.

\section{Declaration of interest}

The authors declare that there is no conflict of interest that could be perceived as prejudicing the impartiality of the research reported.

\section{Funding}

This research was supported by The State of São Paulo Research Foundation (FAPESP) \#2006/60101-1.

\section{Acknowledgements}

The authors thank Dr Adauri Brezolin for English revision of the manuscript.

\section{References}

Altomonte J, Richter A, Harbaran S, Suriawinata J, Nakae J, Thung SN, Meseck M, Accili D \& Dong H 2003 Inhibition of Foxo1 function is associated with improved fasting glycemia in diabetic mice. American Journal of Physiology 285 E718-E728. (doi:10.1152/ajpendo.00156.2003)

Andjelković M, Alessi DR, Meier R, Fernandez A, Lamb NJ, Frech M, Cron P, Cohen P, Lucocq JM \& Hemmings BA 1997 Role of translocation in the activation and function of protein kinase B. Journal of Biological Chemistry 272 31515-31524. (doi:10.1074/jbc.272.50.31515)

Andrews NC \& Faller DV 1991 A rapid micropreparation technique for extraction of DNA-binding proteins from limiting numbers of mammalian cells. Nucleic Acids Research 19 2499. (doi:10.1093/nar/19.9.2499)

Anhê GF, Hirabara SM, Turrer TC, Caperuto LC, Anhê FF, Ribeiro LM, Marçal AC, Carvalho CR, Curi R, Machado UF et al. 2007 Postpartum glycemic homeostasis in early lactating rats is accompanied by transient and specific increase of soleus insulin response through IRS2/AKT pathway. American Journal of Physiology 292 R2225-R2233. (doi:10.1152/ajpregu. 00902.2006)

Barthel A \& Schmoll D 2003 Novel concepts in insulin regulation of hepatic gluconeogenesis. American Journal of Physiology 285 E685-E692. (doi:10. 1152/ajpendo.00253.2003)

Berger J, Biswas C, Vicario PP, Strout HV, Saperstein R \& Pilch PF 1989 Decreased expression of the insulin-responsive glucose transporter in diabetes and fasting. Nature 340 70-72. (doi:10.1038/340070a0)

Biggs WH III, Meisenhelder J, Hunter T, Cavenee WK \& Arden KC 1999 Protein kinase B/Akt-mediated phosphorylation promotes nuclear exclusion of the winged helix transcription factor FKHR1. PNAS 96 7421-7426. (doi:10.1073/pnas.96.13.7421)

Bitar MS 2001 Co-administration of etomoxir and RU-486 mitigates insulin resistance in hepatic and muscular tissues of STZ-induced diabetic rats. Hormone and Metabolic Research 33 577-584. (doi:10.1055/s-2001-17903)

Björnholm M \& Zierath JR 2005 Insulin signal transduction in human skeletal muscle: identifying the defects in type II diabetes. Biochemical Society Transactions 33 354-357. (doi:10.1042/BST0330354)

Blondel O \& Portha B 1989 Early appearance of in vivo insulin resistance in adult streptozotocin-injected rats. Diabetes and Metabolism 15 382-387.

Brunet A, Bonni A, Zigmond MJ, Lin MZ, Juo P, Hu LS, Anderson MJ, Arden KC, Blenis J \& Greenberg ME 1999 Akt promotes cell survival by phosphorylating and inhibiting a Forkhead transcription factor. Cell 96 857-868. (doi:10.1016/S0092-8674(00)80595-4)

Burcelin R, Eddouks M, Maury J, Kande J, Assan R \& Girard J 1995 Excessive glucose production, rather than insulin resistance, accounts for hyperglycaemia in recent-onset streptozotocin-diabetic rats. Diabetologia $\mathbf{3 8}$ 283-290. (doi:10.1007/BF00400632)

Camps M, Castelló A, Muñoz P, Monfar M, Testar X, Palacín M \& Zorzano A 1992 Effect of diabetes and fasting on GLUT-4 (muscle/fat) glucosetransporter expression in insulin-sensitive tissues. Heterogeneous response in heart, red and white muscle. Biochemical Journal 282 765-772.

Carvalho E, Kotani K, Peroni OD \& Kahn BB 2005 Adipose-specific overexpression of GLUT4 reverses insulin resistance and diabetes in mice lacking GLUT4 selectively in muscle. American Journal of Physiology $\mathbf{2 8 9}$ E551-E561. (doi:10.1152/ajpendo.00116.2005)

DeFronzo RA 1997 Insulin resistance: a multifaceted syndrome responsible for NIDDM, obesity, hypertension, dyslipidaemia and atherosclerosis. Netherlands Journal of Medicine 50 191-197. (doi:10.1016/S03002977(97)00012-0)

Diabetes Control and Complications Trial Research Group 2001 Influence of intensive diabetes treatment on body weight and composition of adults with type 1 diabetes in the Diabetes Control and Complications Trial. Diabetes Care 24 1711-1721. (doi:10.2337/diacare.24.10.1711)

Federiuk IF, Casey HM, Quinn MJ, Wood MD \& Ward WK 2004 Induction of type-1 diabetes mellitus in laboratory rats by use of alloxan: route of administration, pitfalls, and insulin treatment. Comparative Medicine $\mathbf{5 4}$ 252-257. 
Ferguson RE, Carroll HP, Harris A, Maher ER, Selby PJ \& Banks RE 2005 Housekeeping proteins: a preliminary study illustrating some limitations as useful references in protein expression studies. Proteomics 5 566-571. (doi:10.1002/pmic.200400941)

Gerich JE 2010 Role of the kidney in normal glucose homeostasis and in the hyperglycaemia of diabetes mellitus: therapeutic implications. Diabetic Medicine 27 136-142. (doi:10.1111/j.1464-5491.2009.02894.x)

Girard J 2006 Insulin's effect on the liver: "direct or indirect"? Continues to be the question Journal of Clinical Investigation 116 302-324. (doi:10.1172/ JCI27743)

Guo S, Copps KD, Dong X, Park S, Cheng Z, Pocai A, Rossetti L, Sajan M, Farese RV \& White MF 2009 The Irs1 branch of the insulin signaling cascade plays a dominant role in hepatic nutrient homeostasis. Molecular and Cellular Biology 29 5070-5083. (doi:10.1128/MCB.00138-09)

Huang S \& Czech MP 2007 The GLUT4 glucose transporter. Cell Metabolism 5 237-252. (doi:10.1016/j.cmet.2007.03.006)

Kainulainen H, Komulainen J, Joost HG \& Vihko V 1994 Dissociation of the effects of training on oxidative metabolism, glucose utilization and GLUT4 levels in skeletal muscle of streptozotocin-diabetic rats. Pflügers Archiv $\mathbf{4 2 7}$ 444-449. (doi:10.1007/BF00374259)

Kubota N, Tobe K, Terauchi Y, Eto K, Yamauchi T, Suzuki R, Tsubamoto Y, Komeda K, Nakano R, Miki H et al. 2000 Disruption of insulin receptor substrate 2 causes type 2 diabetes because of liver insulin resistance and lack of compensatory beta-cell hyperplasia. Diabetes 49 1880-1889. (doi:10. 2337/diabetes.49.11.1880)

Kubota N, Kubota T, Itoh S, Kumagai H, Kozono H, Takamoto I, Mineyama T, Ogata H, Tokuyama K, Ohsugi M et al. 2008 Dynamic functional relay between insulin receptor substrate 1 and 2 in hepatic insulin signaling during fasting and feeding. Cell Metabolism 8 49-64. (doi:10.1016/j.cmet. 2008.05.007)

Ledwig D, Müller H, Bischoff H \& Eckel J 2002 Early acarbose treatment ameliorates resistance of insulin-regulated GLUT4 trafficking in obese Zucker rats. European Journal of Pharmacology 445 141-148. (doi:10.1016/ S0014-2999(02)01714-4)

Lenzen S 2008 The mechanisms of alloxan- and streptozotocin-induced diabetes. Diabetologia 51 216-226. (doi:10.1007/s00125-007-0886-7)

Liu HY, Cao SY, Hong T, Han J, Liu Z \& Cao W 2009 Insulin is a stronger inducer of insulin resistance than hyperglycemia in mice with type 1 diabetes mellitus (T1DM). Journal of Biological Chemistry 284 27090-27100. (doi:10.1074/jbc.M109.016675)

Liu J, Wu X, Franklin JL, Messina JL, Hill HS, Moellering DR, Walton RG, Martin M \& Garvey WT 2010 Mammalian Tribbles homolog 3 impairs insulin action in skeletal muscle: role in glucose-induced insulin resistance. American Journal of Physiology 298 E565-E576. (doi:10.1152/ajpendo. 00467.2009)

Machado UF, Shimizu I \& Saito M 1994 Reduced content and preserved translocation of glucose transporter (GLUT4) in white adipose tissue of obese mice. Physiology \& Behaviour 55 621-625. (doi:10.1016/00319384(94)90035-3)

Meyer C, Stumvoll M, Nadkami V, Dostou J, Mitrakou A \& Gerich J 1998 Abnormal renal and hepatic glucose metabolism in type 2 diabetes mellitus. Journal of Clinical Investigation 102 619-624. (doi:10.1172/JCI2415)

Michael MD, Kulkarni RN, Postic C, Previs SF, Shulman GI, Magnuson MA \& Kahn CR 2000 Loss of insulin signaling in hepatocytes leads to severe insulin resistance and progressive hepatic dysfunction. Molecular Cell 6 87-97. (doi:10.1016/S1097-2765(05)00015-8)

Mori RC, Hirabara SM, Hirata AE, Okamoto MM \& Machado UF 2008 Glimepiride as insulin sensitizer: increased liver and muscle responses to insulin. Diabetes, Obesity \& Metabolism 10 596-600. (doi:10.1111/j.14631326.2008.00870.x)

Mounier C \& Posner BI 2006 Transcriptional regulation by insulin: from receptor to the gene. Canadian Journal of Physiology and Pharmacology 115 713-724. (doi:10.1139/y05-152)

Nakae J, Kitamura T, Silver DL \& Accili D 2001 The forkhead transcription factor Foxo1 (Fkhr) confers insulin sensitivity onto glucose-6-phosphatase expression. Journal of Clinical Investigation 108 1359-1367. (doi:10.1172/ JCI200112876)
O'Brien RM, Streeper RS, Ayala JE, Stadelmaier BT \& Hornbuckle LA 2001 Insulin-regulated gene expression. Biochemical Society Transactions 29 552-558. (doi:10.1042/BST0290552)

Pfaffl MW 2001 A new mathematical model for relative quantification in real-time RT-PCR. Nucleic Acids Research 29 e45. (doi:10.1093/nar/ 29.9.e45)

Purnell JQ, Hokanson JE, Marcovina SM, Steffes MW, Cleary PA \& Brunzell JD 1998 Effect of excessive weight gain with intensive therapy of type 1 diabetes on lipid levels and blood pressure: results from the DCCT. Diabetes Control and Complications Trial. Journal of the American Medical Association 280 140-146. (doi:10.1001/jama. 280.2.140)

Shepherd PR, Gnudi L, Tozzo E, Yang H, Leach F \& Kahn BB 1993 Adipose cell hyperplasia and enhanced glucose disposal in transgenic mice overexpressing GLUT4 selectively in adipose tissue. Journal of Biological Chemistry 268 22243-22246.

Sivitz WI, DeSautel SL, Kayano T, Bell GI \& Pessin JE 1989 Regulation of glucose transporter messenger RNA in insulin-deficient states. Nature $\mathbf{3 4 0}$ 72-74. (doi:10.1038/340072a0)

Taniguchi CM, Ueki K \& Kahn R 2005 Complementary roles of IRS-1 and IRS-2 in the hepatic regulation of metabolism. Journal of Clinical Investigation 115 718-727. (doi:10.1172/JCI200523187)

Taniguchi CM, Emanuelli B \& Kahn CR 2006 Critical nodes in signalling pathways: insights into insulin action. Nature Reviews. Molecular Cell Biology 7 85-96. (doi:10.1038/nrm1837)

Uruska A, Araszkiewicz A, Zozulinska-Ziolkiewicz D, Uruski P \& WieruszWysocka B 2010 Insulin resistance is associated with microangiopathy in type 1 diabetic patients treated with intensive insulin therapy from the onset of disease. Experimental and Clinical Endocrinology and Diabetes 118 478-484. (doi:10.1055/s-0030-1249635)

Valverde AM, Burks DJ, Fabregat I, Fisher TL, Carretero J, White MF \& Benito M 2003 Molecular mechanisms of insulin resistance in IRS-2-deficient hepatocytes. Diabetes 52 2239-2248. (doi:10.2337/diabetes.52.9.2239)

Van Der Heide LP, Hoekman MF \& Smidt MP 2004 The ins and outs of FoxO shuttling: mechanisms of FoxO translocation and transcriptional regulation. Biochemical Journal 380 297-309. (doi:10.1042/ BJ20040167)

Vidal-Puig A \& O'Rahilly S 2001 Metabolism: controlling the glucose factory. Nature 13 125-126. (doi:10.1038/35093198)

Wallberg-Henriksson H \& Zierath JR 2001 GLUT4: a key player regulating glucose homeostasis? Insights from transgenic and knockout mice Molecular Membrane Biology 18 205-211. (doi:10.1080/09687680 110072131)

Withers DJ, Gutierrez JS, Towery H, Burks DJ, Ren JM, Previs S, Zhang Y, Bernal D, Pons S, Shulman GI et al. 1998 Disruption of IRS-2 causes type 2 diabetes in mice. Nature 391 900-904. (doi:10.1038/36116)

Yeagley D, Guo S, Unterman T \& Quinn PG 2001 Gene- and activationspecific mechanisms for insulin inhibition of basal and glucocorticoidinduced insulin-like growth factor binding protein-1 and phosphoenolpyruvate carboxykinase transcription. Roles of forkhead and insulin response sequences. Journal of Biological Chemistry 276 33705-33710. (doi:10.1074/jbc.M101215200)

Zanquetta MM, Nascimento ME, Mori RC, D'Agord Schaan B, Young ME \& Machado UF 2006 Participation of beta-adrenergic activity in modulation of GLUT4 expression during fasting and refeeding in rats. Metabolism 55 1538-1545. (doi:10.1016/j.metabol.2006. 06.026)

Received in final form 22 June 2011

Accepted 11 July 2011

Made available online as an Accepted Preprint 11 July 2011 